\title{
Media freedom and democracy in the fight against corruption ${ }^{\text {is }}$
}

\author{
Sambit Bhattacharyya ${ }^{\mathrm{a}, 1}$, Roland Hodler ${ }^{\mathrm{b}, \mathrm{c}, *}$ \\ a Department of Economics, University of Sussex, Jubilee Building, Brighton BN1 9SL, United Kingdom \\ ${ }^{\mathrm{b}}$ Department of Economics, University of St. Gallen, Bodanstrasse 8, 9000 St. Gallen, Switzerland \\ c CESifo, Munich, Germany
}

\section{A R T I C L E I N F O}

\section{Article history:}

Received 21 February 2014

Received in revised form 8 December 2014

Accepted 16 March 2015

Available online 24 March 2015

\section{JEL classification:}

D72

D73

H11

Keywords:

Corruption

Media freedom

Democratization

Political institutions

\begin{abstract}
A B S T R A C T
Democratization and media freedom have been suggested as useful tools in the fight against political corruption, but so far their interplay in this fight has received scant attention. We present a game theoretic model which allows for varying quality of media freedom and democratic institutions. The model predicts, among others, that democratization and media freedom are complements in the fight against political corruption. We test our theoretical predictions using differences-in-differences estimations and panel data covering 129 countries from 1980 to 2007. We find evidence of causal effects of democratization and media freedom on corruption, and that the two are complements. Our main results hold after controlling for income, country fixed effects, and continent-specific time-varying shocks.
\end{abstract}

(c) 2015 Elsevier B.V. All rights reserved.

\section{Introduction}

Many politicians in office seem to have a tendency to engage in corruption and to appropriate public funds. Democratization is often considered to be a powerful tool in the fight against political corruption (e.g., Treisman, 2000), as regular fair elections give the public the option of removing incumbent politicians from office if significant government malfeasance is discovered. Also media freedom is generally seen as a useful tool (e.g., Brunetti and Weder, 2003), as a free and independent media can play a crucial role in uncovering corrupt behavior and informing the public. We study how the interplay between democratization and media freedom impacts upon political corruption. The main question of interest is whether democratization and media freedom are complements or substitutes in the fight against political corruption. In other words, do we need both a democratic environment with regular fair elections and a free and independent media to curb corruption, or is one of the two enough?

We investigate both theoretically and empirically the relationship between democratization, media freedom and political corruption. In the theoretical part, we present a stylized two-period game between politicians and the people. There are some "good" politicians who act in the people's best interest and possibly many more "bad" politicians who primarily care about their own revenues. In period one the incumbent politician chooses the level of corruption. The probability that the people observe the true

\footnotetext{
We gratefully acknowledge comments from two anonymous referees, Kristina Czura, John Earle, as well as the conference and seminar participants in Birmingham, Bonn, Chicago, Glasgow, Manchester, Paris-Dauphine, and Trondheim. All remaining errors are our own.

* Corresponding author at: Department of Economics, University of St. Gallen, Bodanstrasse 8, 9000 St. Gallen, Switzerland. Tel.: + 41712242340 ; fax: + 4171224 2298.

E-mail addresses: s.bhattacharyya@sussex.ac.uk (S. Bhattacharyya), roland.hodler@unisg.ch (R. Hodler).

1 Tel.: + 441273 872668; fax: + 441273873715 .
} 
level of corruption increases in media freedom. The people then update their belief about the incumbent's type, and they decide whether to support the incumbent or his challenger. The people's decision and the quality of the democratic institutions determine the probability that the incumbent can stay in office in period two. We define democratic institutions to be of high quality if the incumbent is likely to stay in office when supported by the people, but unlikely to stay without the people's support. We find that the equilibrium level of corruption decreases in media freedom and the quality of the democratic institutions. Moreover, democratic institutions are more effective in preventing corruption if the media is free, and media freedom is more effective if democratic institutions are sound. Hence, the model predicts that democratization and media freedom are complements in the fight against political corruption.

In the empirical part we test our theoretical predictions using differences-in-differences estimations and panel data covering 129 countries from 1980 to 2007. Our estimates confirm that both democratization and media freedom have a negative effect on corruption. We argue that these effects are causal. We also find strong joint effects, and document evidence for complementarity between democratization and media freedom. Our main results hold after controlling for income, country fixed effects, and continentspecific time-varying shocks.

Our theoretical part builds on political agency models in the tradition of Barro (1973) and Ferejohn (1986). ${ }^{2}$ There are however several noteworthy differences. First, we assume that voting is forward-looking rather than retrospective. Second, we follow Aidt et al. (2008) and Bhattacharyya and Hodler (2010) in allowing for varying degrees of the quality of democratic institutions and, thereby, imperfect democratic institutions. Third, we allow for varying degrees of media freedom and, hence, different probabilities that the people get accurate information about government behavior. Our model is further related to the models of Vaidya (2005) and Besley and Prat (2006), in which the incumbent government can collude with the media or capture it to ensure that corrupt activities are not reported. In contrast to these models, we take the quality of media reporting as exogenous, but focus on how it interacts with the quality of democratic institutions in determining the level of political corruption.

There exists a large empirical literature on the determinants of corruption. ${ }^{3}$ Our study is most closely related to contributions focusing on the effects of democracy and media freedom on corruption. Based on cross-country data, Treisman (2000) and Paldam (2002) find evidence that exposure to democracy lowers corruption; Brunetti and Weder (2003) and Freille et al. (2007) find that higher media freedom lowers corruption; and Chowdhury (2004) finds that democracy and media freedom both reduce corruption. ${ }^{4}$

The contribution closest to ours is Adserà et al. (2003). Motivated by a political agency model, they present empirical evidence that democratic institutions and the free circulation of daily newspapers curb corruption in a panel data of around 130 countries and 17 years. From a theoretical perspective, two important differences are that democratic institutions are more explicitly captured in our model, and that our model predicts democratization and media freedom to be complements in the fight against corruption. From an empirical perspective, a first important difference is the use of differences-in-differences estimations instead of pooled OLS. The use of a differences-in-differences design as opposed to pooled OLS allows us to interpret our results as causal effects. A second difference in the empirical part is again our focus on the complementarity between democratization and media freedom in the fight against corruption.

The remainder of the paper is structured as follows: Section 2 presents the theoretical model. Section 3 derives the equilibrium and some testable predictions. Section 4 discusses our empirical strategy and data. Section 5 presents the results. Section 6 briefly concludes.

\section{The model}

There is an economy inhabited by three players: an incumbent president, who is in office for exogenous reasons, a challenger, and the people. Each of the two politicians $i \in\{1,2\}$ is a good type $\theta_{i}=\bar{\theta}$ with probability $\alpha \in(0,1)$, and a bad type $\theta_{i}=\underline{\theta}$ with probability $1-\alpha$. Their types $\theta_{i}$ are private information, but $\alpha$ is common knowledge. ${ }^{5}$

For simplicity, we assume that there are only two periods $t \in\{1,2\}$, and we abstract from discounting. We present a two-period version with discounting as well as an infinite-horizon version with discounting in Appendix A. In each period $t$ the politician in office $i$ can decide whether to abstain from corruption, which is in the interest of the people, or to engage in corruption and the expropriation of public funds. That is, he can choose the level of corruption $c_{t}\left(\theta_{i}\right) \in\{0, \kappa\}$, with 0 representing absence of corruption and $\kappa$ representing considerable corruption. ${ }^{6}$

\footnotetext{
${ }^{2}$ See Persson and Tabellini (2000, chapter 4) and Besley (2007, chapter 3) for excellent reviews of political agency models.

${ }^{3}$ Early contributions to this literature include Ades and Di Tella (1997, 1999), La Porta et al. (1999), Rose-Ackerman (1999), and Treisman (2000). Bardhan (1997) and Aidt (2003) provide excellent surveys.

${ }^{4}$ Luechinger et al. (2008) find that bureaucratic rents measured with life satisfaction data also depend on institutional and political constraints. Bhattacharyya and Hodler (2010) find that democratic institutions lower the positive effect of natural resource rents on corruption. Goel et al. (2012) look at the relationship between corruption awareness measured with internet searches and corruption. Their results suggest that corruption awareness has similar effects as media freedom. There are also interesting national level studies on the interplay of democracy and media freedom. Ferraz and Finan (2008) measure how publicly released audits of local government expenditures affect electoral outcomes in Brazilian municipalities. They find that the negative effect of reported incidences of corruption on the political incumbent's reelection chances is larger in municipalities with their own local media outlets. Focusing on Spanish municipalities, Costas-Pérez et al. (2012) study how the effects of corruption scandals on electoral outcomes depend on press coverage and judicial charges. Looking at a panel of Indian states, Besley and Burgess (2002) find that political competition and newspaper circulation increase government responsiveness to falls in food production and crop flood damage (but they do not look at the effects on corruption). Complementarily, Choe and Raschky (2011) find that better democratic institutions and more media activity increase the government's response to major cholera epidemics.

${ }^{5}$ Equilibrium behavior is independent of the value of $\alpha$ as long as $\alpha \in(0,1)$. Hence, it is the same even if good politicians are rare.

${ }^{6}$ Results remain qualitatively unchanged if the low corruption level is strictly positive, or if we allow for multiple corruption levels or even a continuum of them.
} 
The instantaneous von Neumann-Morgenstern utility of the people and the politician in office are $w_{t}=w\left(c_{t}\right)$ and $u_{t}=u\left(c_{t}, \theta_{i}\right)$, respectively. The people are better off in the absence of corruption than in its presence, i.e., $w(0)>w(\kappa)$. A good politician in office is also better off in the absence of corruption, i.e., $u(0, \bar{\theta})>\max \{u(\kappa, \bar{\theta}), 0\}$. The idea is that he values the well-being of the people, and that corrupt activities lead to moral costs that outweigh his material benefits. In contrast, a bad politician in office is better off with corruption, i.e., $u(\kappa, \underline{\theta})>u(0, \underline{\theta})>0$, as he enjoys spending expropriated public funds almost as much as spending his official salary. The ratio $\phi \equiv \frac{u(0, \underline{\theta})}{u(\kappa, \underline{\theta})} \in(0,1)$ measures the utility of a bad incumbent in office when abstaining from corruption relative to his utility when acting corruptly. This ratio depends on the economic and political environment, and is drawn from the uniform distribution on the unit interval. The instantaneous utility of politicians out of office is normalized to zero.

The people observe the true level of corruption $c_{1}$ with probability $\Pi$, and they observe no evidence of corruption independently of its true level with probability $1-\Pi$. Denoting the observed level of corruption by $\hat{c}_{t}$, it follows that $\hat{c}_{t}=c_{t}$ with probability $\Pi$, and $\hat{c}_{t}=$ 0 with probability $1-\Pi$. Occasionally, the people may directly observe some corrupt activities. To a large extent, however, they have to rely on the information about government behavior reported in the media; and the probability that the media uncovers corrupt actives and publishes the evidence increases in the freedom enjoyed by the media. We thus assume $\Pi=M$, where $M \in[0,1]$ measures media freedom. ${ }^{7}$

The quality of democratic institutions determines the chances that the people's favored candidate ends up in office. We assume that the incumbent can stay in office with probability $p$ if the people support him, and with probability $q$ if the people support the challenger, where $0 \leq q \leq p \leq 1$. We use $D \equiv p-q$ to measure the quality of democratic institutions. This measure implies that democratic institutions are sound if the incumbent can stay in office if and only if the people want him to stay; and that democratic institutions are poor if the people's preferences have only a small effect on the chances that the incumbent can stay in office.

The timing and the players' actions are as follows: In period one nature first draws ratio $\phi$, which is observed by all players. ${ }^{8}$ The incumbent then chooses the level of corruption $c_{1}\left(\theta_{I}\right)$. Nature and media freedom then determine the level of corruption $\hat{c}_{1}$ observed by the people. The people then update their belief $\mu\left(\bar{\theta} \mid \hat{c}_{1}\right)$ that the incumbent is a good type, and they decide whether to support the incumbent or the challenger. Thereby we assume that they support the incumbent when indifferent. ${ }^{9}$ Nature, the quality of the democratic institutions and the people's decision then determine the politician in office in period two. In period two the politician in office $i$ chooses $c_{2}\left(\theta_{i}\right)$. Finally, payoffs are realized and the game ends.

The appropriate solution concept for our dynamic game of incomplete information is perfect Bayesian equilibria (PBE), and we focus on equilibria that satisfy the Cho-Kreps intuitive criterion.

\section{Equilibrium}

We use backward induction and start by solving the period two subgame. The politician who is in office in period two has no strategic incentives and simply chooses the level of corruption $c_{2}\left(\theta_{i}\right)$ that maximizes his payoff. It directly follows from $u(0, \bar{\theta})>u(\kappa, \bar{\theta})$ and $u(0, \underline{\theta})<u(\kappa, \underline{\theta})$ :

Lemma 1. In period two, a good politician in office chooses $c_{2}(\bar{\theta})=0$ and a corrupt politician in office chooses $c_{2}(\underline{\theta})=\kappa$.

That is, a good politician abstains from corruption in period two, while a bad politician engages in corruption and the expropriation of public funds.

It follows from Lemma 1 and $w(0)>w(\kappa)$ that the people are better off in period two with a good politician in office. Hence they support the incumbent at the end of period one if and only if their updated belief that he is a good type exceeds the probability that the challenger is a good type, i.e., if and only if $\mu\left(\bar{\theta} \mid \hat{c}_{1}\right) \geq \alpha$.

We now turn to the incumbent's choice of the level of corruption $c_{1}\left(\theta_{I}\right)$ in period one. A good incumbent would like his instantaneous utility $u\left(c_{1}, \bar{\theta}\right)$ to be high, and to ensure the people's support. His instantaneous utility is maximized by $c_{1}(\bar{\theta})=0$. Moreover, Bayes' rule implies that the people's updated belief must satisfy $\mu(\bar{\theta} \mid 0) \geq \alpha$ whenever $c_{1}(\bar{\theta})=0$. Therefore we focus on PBE in which a good incumbent abstains from corruption and plays $c_{1}(\bar{\theta})=0$ (Proposition 1 below confirms that no other PBE exist.).

It remains to determine the level of corruption that a bad incumbent chooses. We first derive the expected lifetime utility of a bad incumbent who abstains from corruption in period one. In this case it holds that $c_{1}(\underline{\theta})=c_{1}(\bar{\theta})=0$, and the media will be unable to find and publish any evidence of corruption, independently of media freedom $M$ and the incumbent's type $\theta_{\mathrm{I}}$. As a consequence, the people observe $\hat{c}_{1}=0$ with probability one, and they cannot learn anything about the incumbent's type. Hence, their updated belief that the incumbent is good is $\mu(\bar{\theta} \mid 0)=\alpha$. They thus support the incumbent, who can therefore stay in office with probability $p$. Consequently, the expected lifetime utility of a bad incumbent who plays $c_{1}(\underline{\theta})=0$ in period one is $U(0, \kappa, \underline{\theta})=u(0, \underline{\theta})+p u(\kappa, \underline{\theta})$.

We now derive the expected lifetime utility of a bad incumbent who decides to engage in corruption already in period one. In this case the people observe $\hat{c}_{1}=\kappa$ with probability $M$ and $\hat{c}_{1}=0$ with probability $1-M$ if the incumbent is bad, and $\hat{c}_{1}=0$ with probability one if the incumbent is good. Therefore, the people know that the incumbent must be bad if they observe $\hat{c}_{1}=\kappa$, i.e., $\mu(\bar{\theta} \mid \kappa)=0$.

\footnotetext{
${ }^{7}$ Results remain qualitatively unchanged if we assume $\Pi=\pi_{0}+\left(\pi_{1}-\pi_{0}\right) M$ with $0<\pi_{0}<\pi_{1}<1$, such that the people may observe some corrupt actives even if $M=0$, and may not observe some corrupt activities even if $M=1$.

${ }^{8}$ We assume that $\phi$ remains unchanged in period two. This assumption is without loss of generality, as equilibrium behavior in period two is the same for any $\phi \in(0,1)$.

9 To motivate this tie-breaking rule, we could, e.g., assume that there is a tiny probability $\varepsilon \rightarrow 0$ that the challenger is an extreme kleptocrat who chooses an excessive level of corruption $K$ leading to $w(K)<w(\kappa)$.
} 
In this case the people support the challenger, such that the incumbent can only stay in office with probability $q$. If they observe $\hat{c}_{1}=0$, then it follows from Bayes' rule that the people's updated belief that the incumbent is good is $\mu(\bar{\theta} \mid 0)=\frac{\alpha}{\alpha+(1-\alpha)(1-M)}>\alpha$. The people thus support the incumbent, who can then stay in office with probability $p$. Consequently, a bad incumbent playing $c_{1}(\underline{\theta})=\kappa$ can stay in office with probability $(1-M) p+M q$, and his expected lifetime utility is $U(\kappa, \kappa, \underline{\theta})=[1+(1-M) p+M q] u(\kappa, \underline{\theta})$.

A bad incumbent is better off playing $c_{1}(\underline{\theta})=0$ in period one if $U(0, \kappa, \underline{\theta}) \geq U(\kappa, \kappa, \underline{\theta})$, and playing $c_{1}(\underline{\theta})=\kappa$ otherwise. ${ }^{10}$ Using $D \equiv p-q$ and $\phi \equiv \frac{u(0, \underline{\theta})}{u(\kappa, \underline{\theta})}$, it can easily be shown that $U(0, \kappa, \underline{\theta}) \geq U(\kappa, \kappa, \underline{\theta})$ holds if and only if $D M \geq 1-\phi .{ }^{11}$ Hence, equilibrium behavior can be characterized as follows:

Proposition 1. There exists a PBE in which a good incumbent plays $c_{1}(\bar{\theta})=0$, a bad incumbent plays $c_{1}(\underline{\theta})=0$ if $D M \geq 1-\phi$, and $c_{1}(\underline{\theta})=\kappa$ otherwise, and the people support the incumbent if and only if they observe $\hat{c}_{1}=0$. There exist no other PBE that satisfies the intuitive criterion.

Proof. The existence of the PBE characterized in Proposition 1 is already established in the discussion leading to Proposition 1, but it remains to prove that no other PBE satisfies the intuitive criterion. The discussion leading to Proposition 1 shows that there cannot exist any other PBE with $c_{1}(\bar{\theta})=0$ than the one characterized in Proposition 1 . We next prove that no PBE with $c_{1}(\bar{\theta})=\kappa$ can satisfy the intuitive criterion. A necessary condition for a good incumbent to play $c_{1}(\bar{\theta})=\kappa$ is that the people support the challenger when observing $\hat{c}_{1}=0$, which requires beliefs $\mu(\bar{\theta} \mid 0)<\alpha$. However, playing $c_{1}(\underline{\theta})=0$ is equilibrium-dominated for a bad incumbent, who plays $c_{1}(\underline{\theta})=\kappa$ and gets reelected in any PBE with $c_{1}(\bar{\theta})=\kappa$, but $c_{1}(\bar{\theta})=0$ is not equilibrium-dominated for a good incumbent. Hence, the intuitive criterion requires beliefs $\mu(\bar{\theta} \mid 0)=1$, which contradicts $\mu(\bar{\theta} \mid 0)<\alpha$. We finally need to prove that there cannot exist any PBE in which a good incumbent plays a mixed strategy in period one. Denote by $\psi(\theta)$ the probability that an incumbent of type $\theta$ chooses $c_{1}(\theta)=0$. We prove by contradiction that there cannot exist any PBE with $\psi(\bar{\theta}) \in(0,1)$. A necessary condition for a good incumbent ever to play $c_{1}(\bar{\theta})=\kappa$ is that the people support the challenger when observing $\hat{c}_{1}=0$. This requires beliefs $\mu(\bar{\theta} \mid 0)<\alpha$, which, in turn, requires $\psi(\underline{\theta})>\psi(\bar{\theta})$ due to Bayes' rule. However, if the people support the challenger when observing $\hat{c}_{1}=0$, a bad incumbent will always choose $c_{1}(\bar{\theta})=\kappa$, i.e., $\psi(\underline{\theta})=0$. There is a contradiction as it cannot simultaneously hold that $\psi(\underline{\theta})>\psi(\bar{\theta})$ and $\psi(\underline{\theta})=0$.

We can think of $D M$ as a measure of corruption control in the economy. The higher $D M$ is, the lower $\operatorname{can} u(0, \underline{\theta})$ be relative to $u(\kappa, \underline{\theta})$ such that a bad incumbent still refrains from corruption in period one. The PBE described in Proposition 1 is therefore pooling if $D M \geq 1-\phi$, and separating otherwise. The reason for the former is that a bad incumbent mimics a good incumbent to ensure the people's support if high media freedom makes the people likely to become informed, if sound democratic institutions make the people's support important for staying in office, and if his short-term utility loss from abstaining from corruption is relatively low. A bad incumbent is however better off engaging in corruption if the media is unlikely to report corrupt activities, or if the people have little effect on the chances that he can stay in office, and if abstaining from corruption leads to a relatively high short-term utility loss.

We next derive the expected level of corruption $c_{1}^{e}$ in this economy, which we measure by the ex-ante probability that the incumbent acts corruptly in period one, with the expectation taken at the beginning of the game:

Proposition 2. Expected corruption is $c_{1}^{e}=(1-\alpha)(1-D M)$. Higher quality of political institutions $D$ and higher media freedom $M$ have negative effects on $c_{1}^{e}$. $D$ and $M$ are complements in that the effect of $D(M)$ gets larger in absolute values as $M(D)$ increases.

Proof. Proposition 1 implies that the probability that $c_{1}=\kappa$ is $1-\alpha$ if $\phi<1-D M$, and zero otherwise. Since $\phi$ is drawn from the uniform distribution on the unit interval, the ex-ante probability that $c_{1}=\kappa$ is $c_{1}^{e}=(1-\alpha)(1-D M)$. It directly follows that $\frac{\partial c_{1}^{e}}{\partial D} \leq 0$, $\frac{\partial c_{1}^{e}}{\partial M} \leq 0$, and $\frac{\partial^{2} c_{1}^{e}}{\partial D \partial M}<0$.

The results that better democratic institutions and a freer media reduce expected corruption is what we would expect. More interestingly, the cross-derivative of expected corruption $c_{1}^{e}$ with respect to $M$ and $D$ is negative as well. That is, an improvement in media freedom is the more valuable in the fight against corruption, the higher the quality of democratic institutions is; and better democratic institutions are the more valuable, the higher media freedom is. Hence, media freedom and democratization are complements in the fight against corruption.

This complementarity is intuitively appealing: Better democratic institutions are not overly helpful to get rid of corrupt incumbent politicians if a suppressed media is unlikely to find and report evidence of corruption. Therefore democratization has little effect on corruption when media freedom is poor. But the situation is very different when media freedom is high. Then, people are likely to learn the true level of corruption and democratization becomes useful to effectively punish corrupt incumbent politicians. As a consequence, engaging in corruption becomes unattractive even for bad incumbents. Democratization is thus more conducive to fighting corruption when the media is free and independent. Symmetrically, improved media freedom is more useful in the fight against corruption if democratic institutions are sound.

\footnotetext{
${ }^{10}$ In the special case in which $U(0, \kappa, \underline{\theta})=U(\kappa, \kappa, \underline{\theta})$, a bad incumbent is indifferent between playing $c_{1}(\underline{\theta})=0$ and $c_{1}(\underline{\theta})=\kappa$.

11 We can rewrite $U(0, \kappa, \underline{\theta}) \geq U(\kappa, \kappa, \underline{\theta})$ as $u(0, \underline{\theta}) \geq[1+M(q-p)] u(\kappa, \underline{\theta})$, which can be simplified to $\phi \geq 1-D M$ and, consequently, $D M \geq 1-\phi$.
} 


\section{Empirical strategy and data}

In the empirical part we use panel data covering 129 countries and annual observations from 1980 to 2007. In order to estimate the causal effects of democratization and media freedom on corruption we follow the differences-in-differences approach used by Giavazzi and Tabellini (2005), Yang (2011), and Bhattacharyya (2013). We estimate the following equation:

$$
C I_{i c t}=\alpha_{i}+\beta_{c t}+\gamma Y_{i c t}+\delta \text { Treatment }_{i c t}+\varepsilon_{i c t}
$$

where $C_{i c t}$ is a corruption index measuring corruption in country $i$ at year $t$, and $Y_{i c t}$ is log per capita GDP in country $i$ at year $t$. The country dummy variables $\alpha_{i}$ represent the use of country fixed effects, which capture all country characteristics that are constant during our sample period. The continent-year dummy variables $\beta_{c t}$ capture all continent-specific as well as global changes over time. ${ }^{12}$ Treatment $_{i c t}$ represents the democratization or media freedom treatment in country $i$. It is equal to zero for pre-treatment years, and equal to one from the treatment year onwards. We use robust standard errors clustered at the country level in order to take account of serial correlation.

If country $i$ receives treatment at time $t=k$, then the conditional expected corruption index in country $i$ before and after the treatment are $E\left(C I_{i c k}-1 \mid\left\{Y_{i c t}\right\}\right)=\alpha_{i}+\beta_{c k-1}$ and $E\left(C I_{i c k} \mid\left\{Y_{i c t}\right\}\right)=\alpha_{i}+\beta_{c k}+\delta$, respectively. The simple difference between the conditional expected corruption indices in country $i$ before and after the treatment is $E\left(C I_{i c k} \mid\left\{Y_{i c t}\right\}\right)-E\left(C I_{i c k}-1 \mid\left\{Y_{i c t}\right\}\right)=\beta_{c k}-\beta_{c k-1}+\delta$. This difference does not allow us to disentangle the effect of the treatment from (other) contemporaneous changes affecting countries on continent $c$. It would require comparing the change in expected corruption in country $i$ with another country $j$ on continent $c$ that did not receive treatment at time $t=k$. For country $j$, the change in expected corruption indices before and after $t=k$ is $E\left(C I_{j c k} \mid\left\{Y_{i c t}\right\}\right)-E\left(C I_{j c k}-1 \mid\left\{Y_{i c t}\right\}\right)=\beta_{c k}-\beta_{c k-1}$. Therefore, the effect of the treatment on the corruption index is given by $\left[E\left(C I_{i c k} \mid\left\{Y_{i c t}\right\}\right)-E\left(C I_{i c k}-1 \mid\left\{Y_{i c t}\right\}\right)\right]-\left[E\left(C I_{j c k} \mid\left\{Y_{i c t}\right\}\right)-E\left(C I_{j c k}-1 \mid\left\{Y_{i c t}\right\}\right)\right]=\delta$. This is the differences-in-differences estimator. Hence, in Eq. (1), $\delta$ represents the impact of the treatment, i.e., democratization or media freedom, on the corruption index. It identifies the systematic differences in corruption with and without the treatment after controlling for country-specific permanent characteristics and continent-specific time-varying developments.

Therefore, the key coefficient of interest is $\delta$. There are three groups of countries in our sample: First, countries experiencing democratization or gaining media freedom or both during the sample period. For these countries Treatment ${ }_{i c t}$ switches from 0 to 1 . Second, countries that were untreated in all years of our sample period. For these countries Treatment ${ }_{i c t}$ is always 0 . Third, countries that were treated in all years during our sample period. For these countries Treatment $t_{i c t}$ is always 1 . The differences-in-differences estimator compares the corruption index in the first group of countries before and after the treatment with the corruption index in the second and the third group of countries during the same time period. Thus this methodology makes use of both within-country as well as between-country variation in the data.

The differences-in-differences estimates can be biased if the treatments are not random, or if the treated and untreated countries are systematically different from each other. The possibility of such biases cannot be ruled out completely in a macro context. ${ }^{13}$ One should be aware of this caveat when interpreting the results. We however take various measures that make us confident that we are estimating unbiased and causal effects. The country and continent-year dummy variables already eliminate biases originating from time-invariant country characteristics and continent-wide developments that may influence both corruption and treatment. In some robustness exercises we further follow Giavazzi and Tabellini (2005), Yang (2011) and Bhattacharyya (2013), and include interaction terms between treatments and SocialistLegalOrigin ${ }_{i c}$, which is a dummy variable by La Porta et al. (1999) that equals one for former Soviet bloc countries. We can thereby control for any systematic effect on corruption and treatment originating from transitional economies that democratized and adopted free media around the same time. ${ }^{14}$ In addition, we look into the timing of the treatment effects, and find that it takes a few years after the treatment before corruption changes. This time lag makes reverse causality rather unlikely.

The treated countries could be systematically different from other countries in the absence of parallel trends prior to treatment. Fig. 1, which shows average corruption in control and treatment countries, provides support for the parallel trend assumption. A figure like those typically presented in micro-econometric (labor-type) applications is not possible in our case. The reason is that the countries receive treatment at different years, so that there is no precise treatment year that allows assigning observations from countries in the control group into the pre- or post-treatment period. Instead we plot in the top panel of Fig. 1 the average corruption in control countries over the period from 1980 to 2007. In the bottom panel we plot average corruption in treated countries from five years before to five years after the treatment year. The trends in corruption in control countries and treatment countries before treatment (i.e., in the period from $t-5$ to $t$ ) are similar. In both panels the trend in the corruption index in countries without media freedom is mostly upward sloping, and the trend in the corruption index in undemocratic countries is slightly downward sloping, suggesting similar trends prior to treatment. In addition, the bottom panel of Fig. 1 already provides some preliminary evidence for our theoretical predictions that democratization and media freedom reduce corruption, i.e., that they increase the corruption index $C I_{i c t}$.

We also perform a battery of placebo tests in which the placebo treatments are administered one to six years in advance of the actual treatment year. If our main results were driven by pre-existing divergent trends between the control and the treatment

\footnotetext{
12 Following Giavazzi and Tabellini (2005), the continent-year dummy variables are based on interaction terms between year dummy variables and dummy variables for the following continents (or parts of the world, respectively): Africa, Asia, Latin America, countries with socialist legal origin, and the rest.

13 Similar methodological caveats were also noted by Giavazzi and Tabellini (2005).

14 See Diabya and Sylwester (2014) for a recent paper on corruption in transition economies.
} 


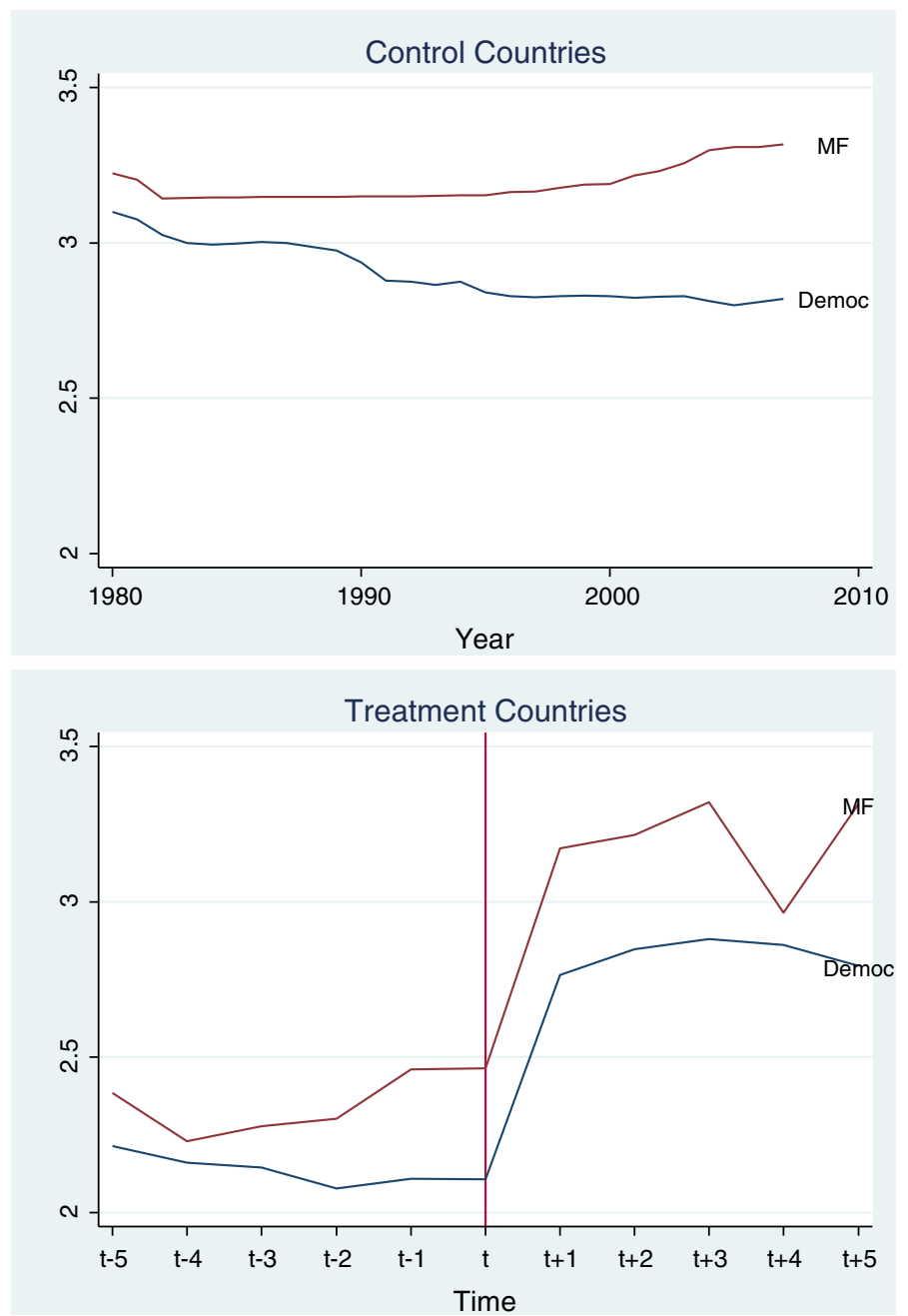

Fig. 1. Average corruption in control and treatment countries. Notes: In the top panel corruption scores are averaged over the period 1980 to 2007 in control countries (i.e., countries that never democratized or never had media freedom during our sample period). In the bottom panel corruption scores are averaged in treatment countries from five years prior to treatment to five years post-treatment.

countries, we would expect these placebo treatments to have significant effects as well. However, as we show below, the effects of the placebo treatments are statistically insignificant in all cases. This finding is contrary to what one would expect in the presence of pre-existing divergent trends. It thereby provides additional indirect support for the parallel trend assumption.

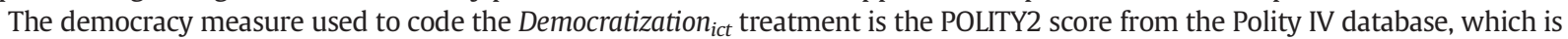
described by Marshall and Jaggers (2002). This database reports democracy and autocracy scores, which both vary between 0 and 10 with 10 being the most democratic or most autocratic, respectively. The democracy score measures competition and openness in the electoral process, and the autocracy score measures suppression of competitiveness over executive recruitment, lack of constraints on the executive, and regulation of participation. The POLITY2 score is the difference between democracy and autocracy scores which runs between -10 and +10 . Following Giavazzi and Tabellini (2005) we define democratization $\left(\right.$ Democratization $\left._{\text {ict }}=1\right)$ in a country if its POLITY2 score turns from negative to positive. One could argue that a positive POLITY2 score is too low a threshold for democratization as most permanent democratic transitions occur at higher scores. To account for this concern, we also test the robustness of our result when a POLITY2 score of 5 is used as democratization threshold.

Following Giavazzi and Tabellini (2005) we consider two types of democratization: First, we consider democratization episodes that are not subsequently reversed. They are denoted as "permanent" treatments in the result tables. Second, we consider both temporary and permanent democratization episodes that last at least four years, as we expect that it takes time for democratic change to influence corruption. They are denoted by the treatment "all" in the result tables. In situations where the democratic change last less than four years, we ignore such change and code it as if it did not occur. Furthermore, again following Giavazzi and Tabellini (2005), we also discard democratic change that took place in the last three years of the sample. The dependent variable in such situations is set to be missing. 
Table 1

Summary statistics.

\begin{tabular}{|c|c|c|c|c|c|c|c|c|}
\hline Variable & $\begin{array}{l}\text { Number } \\
\text { of obs. }\end{array}$ & Mean & $\begin{array}{l}\text { Standard } \\
\text { deviation } \\
\text { (overall) }\end{array}$ & $\begin{array}{l}\text { Standard deviation } \\
\text { (between countries) }\end{array}$ & $\begin{array}{l}\text { Standard deviation } \\
\text { (within countries) }\end{array}$ & $\begin{array}{l}\text { Within and between } \\
\text { standard deviation } \\
\text { ratio (\%) }\end{array}$ & Minimum & Maximum \\
\hline Corruption index $\left(C_{i c t}\right)$ & 2420 & 2.96 & 1.59 & 1.37 & 0.81 & 60 & 0 & 6 \\
\hline Democratization $_{\text {ict }}$ (permanent) & 2420 & 0.55 & 0.49 & 0.43 & 0.25 & 58 & 0 & 1 \\
\hline Democratization $_{\text {ict }}$ (all) & 2420 & 0.59 & 0.49 & 0.42 & 0.26 & 62 & 0 & 1 \\
\hline Media Freedom ${ }_{\text {ict }}$ (permanent) & 2420 & 0.51 & 0.50 & 0.43 & 0.24 & 56 & 0 & 1 \\
\hline Media Freedom $_{\text {ict }}$ (all) & 2420 & 0.59 & 0.49 & 0.41 & 0.29 & 70 & 0 & 1 \\
\hline
\end{tabular}

Our Media Freedom ict treatment is constructed using the media freedom index from the Freedom House, which is widely used and offers the largest country and time coverage. For the period 1980 to 1993, Freedom House classifies a country's electronic and print media as "free", "partly free", or "not free". From 1994 onwards, it reports the Freedom House media freedom index which runs from 0 to 100, with scores between 0 and 30 signifying that the media is "free", scores between 31 and 60 implying "partly free", and scores between 61 and 100 implying "not free". We define Media Freedom ${ }_{i c t}=1$ if Freedom House classifies a country's media to be "free". We also test the robustness of our results when assigning Media Freedomict $=1$ if Freedom House classifies a country's media to be "free" or "partly free". As in case of democratization, we also consider two types of media freedom treatments "permanent" and "all".

We use the corruption index $\left(\mathrm{Cl}_{i c t}\right)$ from the Political Risk Services (PRS) as measure of corruption. This index is based on the subjective analysis of available information and, therefore, a measure of perceived corruption. It is predominantly an assessment of corruption within the political system, and covers most common forms of corruption. ${ }^{15}$ Hence, it suits our purpose as corruption is also part of the political process in the theoretical model. The PRS corruption index covers a relatively long time period and has the largest number of observations, which minimizes potential sample selection bias both across countries and over time. ${ }^{16}$ In addition, it is widely used in the literature (e.g., Adserà et al., 2003; Brunetti and Weder, 2003). The PRS corruption index varies between 0 and 6 , with higher values indicating lower levels of corruption. Averaged over the sample period, the Democratic Republic of Congo was the most corrupt country with an average value of $C I_{i c t}$ of 0.6 , and Finland was the least corrupt country with an average value of $C_{i c t}$ of 6.0.

We control for log GDP per capita in order to account for the impact of economic development on corruption. The GDP per capita PPP data is sourced from the World Bank.

Table 1 reports summary statistics.

\section{Empirical evidence}

We first look at the individual effects of democratization and media freedom on corruption, and then present some evidence on the complementarity of the two in the fight against corruption.

\subsection{Democratization and corruption}

Table 2 presents our differences-in-differences estimates of Democratization ${ }_{\text {ict }}$ on the corruption index $C_{\text {ict. }}$. Column 1 reports the impact of permanent democratization, i.e., democratization treatments that are not subsequently reversed. The statistically significant coefficient estimate of 0.34 suggests that democratization increases the corruption index by two fifths of its within standard deviation. For a country like Senegal with an average corruption score of 2.75 this would mean an increase to 3.09, which corresponds to the sample average.

Some countries experience reversals in treatment especially with regards to democratization. Therefore it is important to capture the effect of this reversal empirically using alternative definitions of treatment. Following Giavazzi and Tabellini (2005) we use an "all" Democratization ${ }_{i c t}$ variable which includes both permanent and temporary democratizations that last at least for four years in column 2 . We see that the coefficient of interest remains positive and statistically significant. In column 3 we include both these Democratization ${ }_{i c t}$ variables to study whether the effect of temporary and permanent democratizations differ. We find that permanent democratizations tend to have stronger negative effects on corruption (as one would expect), but this difference is not statistically significant. ${ }^{17}$

In the left panel on Fig. 2 we investigate the timing of the effect of permanent democratization on corruption. We regress the corruption index on a series of dummy variables representing years before and after democratization. These are three dummy variables for the three years prior to democratization $(t-3, t-2, t-1)$, one dummy variable for the year of democratization $(t)$,

\footnotetext{
${ }^{15}$ For example, patronage, nepotism, job reservations, secret party funding, and bribes connected with export and import licenses, exchange controls, tax assessments, police protection, loans etc.

${ }^{16}$ Transparency International covers more countries than the PRS, but the actual number of observations in the Transparency International dataset is roughly half that of the PRS.

17 The coefficient on the "all" treatment variable captures the effect of temporary treatments of four or more year; and the coefficient on the permanent treatment variable captures the differences between permanent and temporary treatments. Hence the sum of the two coefficients gives the effect of permanent treatments.
} 
Table 2

Democratization and corruption: differences-in-differences estimates.

\begin{tabular}{|c|c|c|c|c|c|}
\hline \multirow[t]{2}{*}{ Dependent variables } & \multicolumn{5}{|c|}{ Corruption index $\left[\mathrm{CI}_{\text {ict }}\right]$} \\
\hline & $\overline{(1)}$ & $(2)$ & (3) & $(4)$ & $(5)$ \\
\hline Democratization $_{\text {ict }}$ (permanent) & $0.34^{* *}(0.18)$ & & $0.09(0.26)$ & & $0.34^{* *}(0.18)$ \\
\hline Democratization $_{\text {ict }}$ (all) & & $0.35^{* *}(0.16)$ & $0.28(0.24)$ & & \\
\hline Democratization $_{\text {ict }}($ Polity2 $=5)$ & & & & $0.40^{* *}(0.21)$ & \\
\hline Socialist Legal Origin $_{i c} \times$ Democratization $_{\text {ict }}($ permanent) & & & & & $0.20(0.62)$ \\
\hline Controls: & \multicolumn{5}{|c|}{ Country dummies, continent-year dummies, log GDP per capita } \\
\hline Countries & 129 & 129 & 129 & 129 & 129 \\
\hline Observations & 2420 & 2420 & 2420 & 2420 & 2420 \\
\hline Adjusted $R^{2}$ & 0.77 & 0.77 & 0.77 & 0.77 & 0.77 \\
\hline
\end{tabular}

Notes: Figures in parentheses are cluster standard errors, and they are robust to arbitrary heteroskedasticity and arbitrary intra-group correlation. ${ }^{* * *}, *^{*}$, and $*$ indicate significance level at $1 \%, 5 \%$, and $10 \%$ respectively against a two sided alternative. Sample years are every year from 1980 to 2007 . Democratization $n_{i c t}=1$ after democratization (i.e., Polity2 score turning positive). We consider two types of democratization: Treatments that are not subsequently reversed are denoted by "permanent", and treatments that last at least four years are denoted by "all". Democratization ${ }_{\text {ict }}$ (Polity2 = 5 ) = 1 after democratization with Polity2 score turning 5 or above. Regressions always include country fixed effects, continent-year dummy variables (with continents given by Asia, Africa, Latin America, Socialist Legal Origin $n_{\text {ic }}$ countries and the rest), and log GDP per capita.

three dummy variables for the first three years after democratization $(t+1, t+2, t+3)$, and one dummy variable for four and more years after democratization $(t+4+)$. The regression also includes country fixed effects, continent-year dummy variables, and log GDP per capita. We find no statistically significant effect on corruption in the three years prior to democratization, the year of democratization and the first year post democratization. The coefficients on the dummy variables for two or more years after democratization are positive, relatively large and highly significant, suggesting that democratization has a lasting negative impact on corruption.

In column 4 of Table 2 we implement a more stringent test of democratization. We look at the effects of permanent democratization on the corruption index when permanent democratization is defined as a country permanently achieving a POLITY2 score of 5 and above (instead of a positive POLITY2 score). The effect of democratization remains qualitatively unchanged and becomes even

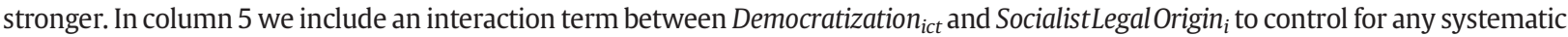
effect on corruption and the treatment originating from the transitional economies. We do not find any evidence that the treatment effect is significantly different in these countries than elsewhere.

In summary, our findings confirm that democratization increases the corruption index, implying a reduction in corruption. The effect appears to be long lasting rather than transitory.

\subsection{Media freedom and corruption}

Table 3 presents our differences-in-differences estimates of Media Freedom ict $_{\text {on }}$ on the corruption index $\mathrm{CI}_{\text {ict }}$. Column 1 reports the impact of permanent media freedom, i.e., media freedom treatments that are not subsequently reversed. The statistically significant coefficient estimate is 0.70 , which is larger than for a democratization treatment. It suggests that permanent media freedom increases the corruption index $\left(\mathrm{Cl}_{\text {ict }}\right)$ by more than four fifths of its within standard deviation.

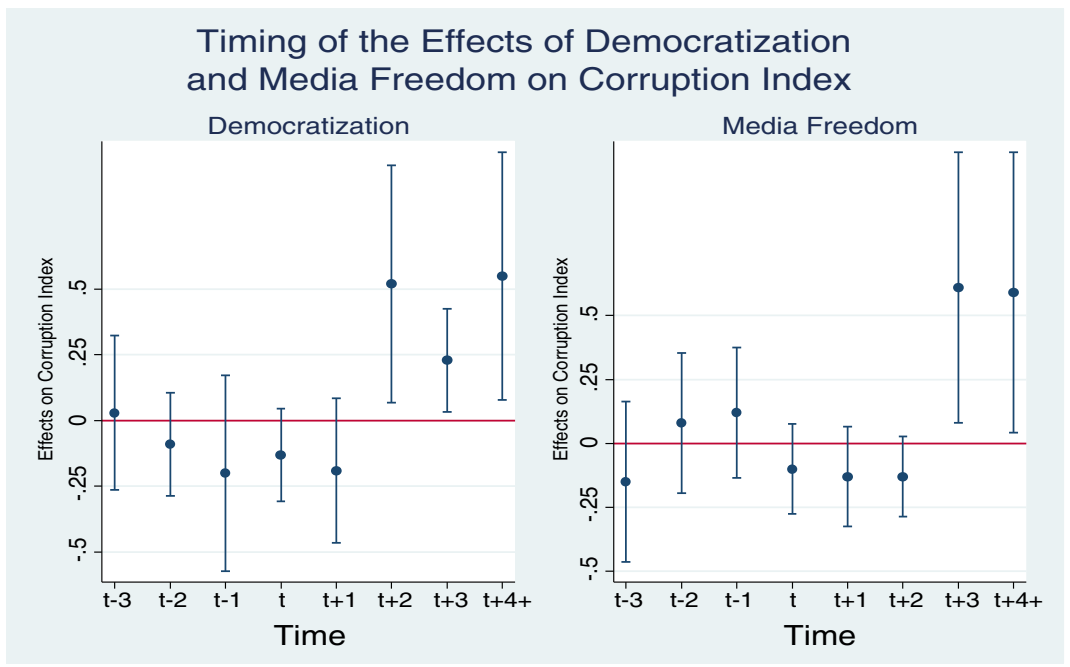

Fig. 2. Timing of the effects of democratization and media freedom on corruption index. Notes: The graphs show the timing of the treatment effects. The corruption index is regressed on three dummy variables taking the value 1 for the three years prior to a treatment, four dummy variables for the four years post treatment, and one dummy variable for five and more years post treatment. The dots show the point estimates, and the bars indicate $95 \%$ confidence intervals. Standard errors in the regressions are clustered and robust. Both regressions include country fixed effects, continent-year dummy variables, and log GDP per capita. 
Table 3

Media freedom and corruption: differences-in-differences estimates.

\begin{tabular}{|c|c|c|c|c|c|}
\hline \multirow[t]{2}{*}{ Dependent variables } & \multicolumn{5}{|c|}{ Corruption index $\left[\mathrm{CI}_{i c t}\right]$} \\
\hline & $(1)$ & $(2)$ & (3) & $(4)$ & $(5)$ \\
\hline Media Freedom $_{\text {ict }}$ (permanent) & $0.70^{* * *}(0.27)$ & & $0.65^{* *}(0.27)$ & & $0.63^{* *}(0.30)$ \\
\hline Media Freedom $_{\text {ict }}($ all $)$ & & $0.33^{* *}(0.14)$ & $0.28^{* *}(0.14)$ & & \\
\hline Media Freedom ict $_{\text {(flexible) }}$ & & & & $0.51^{* * *}(0.20)$ & \\
\hline Socialist Legal Origin $_{i c} \times$ Media Freedom $_{i c t}$ (permanent) & & & & & $0.37(0.67)$ \\
\hline Controls: & \multicolumn{5}{|c|}{ Country dummies, continent-year dummies, log GDP per capita } \\
\hline Countries & 136 & 136 & 136 & 136 & 136 \\
\hline Observations & 2771 & 2771 & 2771 & 2771 & 2771 \\
\hline Adjusted $R^{2}$ & 0.75 & 0.75 & 0.75 & 0.75 & 0.75 \\
\hline
\end{tabular}

Notes: Figures in parentheses are cluster standard errors, and they are robust to arbitrary heteroskedasticity and arbitrary intra-group correlation. ${ }^{* * *}$, ${ }^{*}$, and $*$ indicate significance level at $1 \%, 5 \%$, and $10 \%$ respectively against a two sided alternative. Sample years are every year from 1980 to 2007. Media Freedom ict $=1$ after media freedom treatment, i.e., Freedom House classifies media to be "free". We consider two types of media freedom treatments: Treatments that are not subsequently reversed are denoted by "permanent", and treatments that last at least four years are denoted by "all". Media Freedom ict (flexible) $=1$ after Freedom House classifies media to be "free" or "partly free". Regressions always include country fixed effects, continent-year dummy variables (with continents given by Asia, Africa, Latin America, Socialist Legal Origin ${ }_{i c}$ countries and the rest), and log GDP per capita.

Column 2 estimates the effect of all (permanent and temporary) treatments where the media became free for at least four years. The coefficient becomes smaller, but remains statistically significant. In column 3 we again include both permanent and temporary treatments that last at least four years into the same specification. The results indicate that even temporary media freedom has a statistically significant effect on corruption, and that permanent media freedom has a significantly stronger effect.

In the right panel of Fig. 2 we investigate the timing of the effect of the media freedom treatment using an identical design as in the left panel, where we have explored the timing of the effect of democratization. The media freedom treatment also appears to have no immediate effect on corruption, but a lasting negative effect starting three years after the treatment.

In column 4 of Table 3 we implement a more flexible criterion of media freedom by coding a country's media to be free if Freedom House classifies its media to be "free" or "partly free". The coefficient of interest remains positive and statistically significant. In column 5 we again document that the treatment effect is not significantly different in the transitional economies than elsewhere.

In summary, the evidence in Table 3 and Fig. 2 suggests that media freedom reduces corruption. The effect again appears to be lasting rather than transitory.

\subsection{Complementarity}

Table 4 reports evidence supporting complementarity between democratization and media freedom in the fight against corruption. In column 1 we simultaneously include the two potential treatments, Democratization ict $_{\text {and }}$ Media Freedom ict, $_{\text {, as well as their }}$ interaction. We find that all three coefficients are positive and statistically significant. The large positive coefficient on the interaction term indicates strong complementarity between the two treatments. The estimated coefficients suggest that the corruption index of a country like Senegal would increase from 2.75 all the way up to 5.39 if it received both treatments.

In column 2 we introduce the dummy variables Treatment $1_{\text {ict }}$ and Treatment $2_{\text {ict }}$. The former is equal to one if and only if Democratization $_{i c t}+$ Media Freedom $i c t=1$, and the latter is equal to one if and only if Democratization ict + Media Freedom $_{i c t}=2$.

Table 4

Democratization and media freedom: complements or substitutes in the fight against corruption?

\begin{tabular}{|c|c|c|}
\hline \multirow[t]{2}{*}{ Dependent variables } & \multicolumn{2}{|c|}{ Corruption index $\left[\mathrm{CI}_{i c t}\right]$} \\
\hline & $(1)$ & $(2)$ \\
\hline Democratization $_{\text {ict }}$ & $0.31^{* *}(0.18)$ & \\
\hline Media Freedomict & $0.57^{* *}(0.25)$ & \\
\hline Democratization $_{\text {ict }} \times$ Media Freedom $_{\text {ict }}$ & $1.76^{* * *}(0.63)$ & \\
\hline Treatment $1_{\text {ict }}$ & & $0.19(0.20)$ \\
\hline Treatment $2_{\text {ict }}$ & & $0.63^{* *}(0.26)$ \\
\hline Controls: & \multicolumn{2}{|c|}{ Country dummies, Continent-year dummies, Log GDP per capita } \\
\hline Countries & 129 & 129 \\
\hline Observations & 2420 & 2420 \\
\hline Adjusted $R^{2}$ & 0.77 & 0.77 \\
\hline
\end{tabular}

Notes: Figures in parentheses are cluster standard errors, and they are robust to arbitrary heteroskedasticity and arbitrary intra-group correlation. ${ }^{* * *},{ }^{* *}$, and ${ }^{*}$ indicate significance level at $1 \%, 5 \%$, and $10 \%$ respectively against a two sided alternative. Sample years are every year from 1980 to 2007 . We only consider permanent treatments, i.e., treatments that are not subsequently reversed. Democratization $n_{i c t}=1$ after democratization (i.e., Polity 2 score permanently turning positive). Media Freedom $_{i c t}=1$ after media freedom treatment (i.e., Freedom House classifies media to be "free"). Treatment $1_{\text {ict }}=1$ if one treatment (either democratization or media freedom) is active but not the other. Treatment $2_{\text {ict }}=1$ if both treatments (democratization and media freedom) is active from the country-year onwards in which the second treatment becomes active. All regressions include country fixed effects, continent-year dummies, and log GDP per capita. 
Table 5

Robustness tests.

\begin{tabular}{|c|c|c|c|}
\hline \multirow[t]{2}{*}{ Dependent variables } & \multicolumn{3}{|c|}{ Corruption index $\left[C I_{i c t}\right]$} \\
\hline & $(1)$ & $(2)$ & $(3)$ \\
\hline Democratization $_{\text {ict }}$ & $0.34^{* * *}(0.10)$ & & $0.31^{* * *}(0.12)$ \\
\hline Media Freedom $_{\text {ict }}$ & & $0.70^{* * *}(0.16)$ & $0.57^{* * *}(0.16)$ \\
\hline Democratization $_{\text {ict }} \times$ Media Freedom $_{\text {ict }}$ & & & $1.76^{* * *}(0.56)$ \\
\hline Controls: & \multicolumn{3}{|c|}{ Country dummies, continent-year dummies, log GDP per capita } \\
\hline Iterations & 129 & 136 & 129 \\
\hline Size (with replacement) & 128 & 135 & 128 \\
\hline
\end{tabular}

Notes: Figures in parentheses are bootstrapped standard errors. ${ }^{* * *},{ }^{* *}$, and ${ }^{*}$ indicate significance level at $1 \%, 5 \%$, and $10 \%$ respectively against a two sided alternative. Sample years are every year from 1980 to 2007 . We only consider permanent treatments, i.e., treatments that are not subsequently reversed. Democratization $_{i c t}=1$ after democratization (i.e., Polity 2 score permanently turning positive). Media Freedom $m_{\text {ict }}=1$ after media freedom treatment (i.e., Freedom House classifies media to be "free"). Regressions always include country fixed effects, continent-year dummies, and log GDP per capita. Bootstrap replications performed in each column by taking out one country at a time with replacement.

We thus distinguish between countries that have received only one treatment and countries that have received both treatments, but impose the effects of Democratization $n_{i c t}$ and MediaFreedom ${ }_{i c t}$ to be the same. We find that the coefficient on Treatment $1_{\text {ict }}$ is positive but not statistically significant, while the coefficient on Treatment $2_{\text {ict }}$ is larger and statistically significant. This result implies that both democratization and media freedom are important to curb corruption, and that just one of the two may not be enough.

In summary, we find considerable empirical support for our theoretical prediction that media freedom and democratization are complements in the fight against corruption.

\subsection{Robustness}

To check whether our results are driven by some outlier countries, we conduct a robustness test of our main specifications, i.e., columns 1 of Tables $2-4$, by dropping one country at a time from the sample and re-estimate the model standard errors using bootstrap. ${ }^{18}$ Table 5 shows that the coefficients of interest remain statistically significant in all columns.

Table 6 presents a battery of placebo tests in which placebo treatments are administered one to six years in advance of the actual treatment years. If our main results were driven by pre-existing divergent trends between the control and the treatment countries, we would expect these placebo treatments to have significant effects. But the effects of the placebo treatments are statistically insignificant in all twelve cases. This finding, which is contrary to what one would expect in the presence of pre-existing divergent trends, provides indirect support for the parallel trend assumption.

\section{Conclusions}

Democratization and media freedom have both been suggested as useful tools in the fight against political corruption. However, so far, their interplay in this fight has received scant attention. We have presented a stylized game theoretic model that shows that democratization and media freedom are complements in the fight against political corruption. We have then presented differences-in-differences estimates using panel data covering 129 countries from 1980 to 2007. We find evidence of causal effects of democratization and media freedom on corruption, and that democratization and media freedom appear to be complements rather than substitutes. Hence, the fight against political corruption is hard to win only by democratization, or only by promoting free and independent media. The winning strategy must contain sound democratic institutions and free media.

\section{Appendix A. Infinite-horizon model}

The game-theoretical model presented in Section 2 has only two periods and no discounting. In this appendix, we show that results are qualitatively unchanged in a two-period version of our game with discounting as well as in the corresponding repeated game with infinite horizon. Further, we compare the level of corruption in these two versions of our game.

\section{A.1. Two-period game with discounting}

The setting of the model is identical to the one described in Section 2, except that players have a discount factor $\beta<1$.

The behavior of good and bad politicians in period two remains unchanged. The people's decision and the behavior of a good incumbent in period one remain unchanged as well. However, the expected lifetime utility of a bad incumbent is

\footnotetext{
18 We perform bootstrapping using the following procedure. For a dataset containing $N$ countries a random sample of $N-1$ countries is drawn with replacement and the estimator is applied. This process is repeated $N$ times which yields a dataset of replicated statistics. The standard error is calculated using the sample standard error $\hat{s} e=\sqrt{\frac{1}{N-1} \sum\left(\hat{\theta}_{n}-\bar{\theta}\right)^{2}}$, where $\hat{\theta}_{n}$ is the statistic calculated using the $n$th bootstrap.
} 
Table 6

Placebo tests.

\begin{tabular}{|c|c|c|c|c|c|c|}
\hline \multicolumn{7}{|l|}{ Panel A } \\
\hline \multirow[t]{2}{*}{ Dependent variables } & \multicolumn{6}{|c|}{$\underline{\text { Corruption index }\left[\mathrm{CI}_{i c t}\right]}$} \\
\hline & $(1)$ & $(2)$ & $(3)$ & $(4)$ & $(5)$ & (6) \\
\hline Democratization $_{\text {ict }}$ (Placebo) & $0.09(0.19)$ & $0.11(0.19)$ & $0.12(0.19)$ & $0.14(0.19)$ & $0.19(0.19)$ & $0.22(0.19)$ \\
\hline Placebo treatment delivery & $\mathrm{t}-1$ & $\mathrm{t}-2$ & $\mathrm{t}-3$ & $\mathrm{t}-4$ & $\mathrm{t}-5$ & $\mathrm{t}-6$ \\
\hline Controls: & \multicolumn{6}{|c|}{ Country dummies, continent-year dummies, log GDP per capita } \\
\hline Countries & 129 & 129 & 129 & 129 & 129 & 129 \\
\hline Observations & 2420 & 2420 & 2420 & 2420 & 2420 & 2420 \\
\hline Adjusted $R^{2}$ & 0.78 & 0.77 & 0.77 & 0.76 & 0.75 & 0.76 \\
\hline \multicolumn{7}{|l|}{ Panel B } \\
\hline \multirow[t]{2}{*}{ Dependent variables } & \multicolumn{6}{|c|}{ Corruption index $\left[\mathrm{CI}_{i c t}\right]$} \\
\hline & $(1)$ & $(2)$ & (3) & $(4)$ & $(5)$ & (6) \\
\hline Media Freedom $_{\text {ict }}($ Placebo) & $0.12(0.16)$ & $0.11(0.16)$ & $0.16(0.15)$ & $0.23(0.16)$ & $0.22(0.17)$ & $0.23(0.17)$ \\
\hline Placebo treatment delivery & $\mathrm{t}-1$ & $\mathrm{t}-2$ & $\mathrm{t}-3$ & $\mathrm{t}-4$ & $\mathrm{t}-5$ & $\mathrm{t}-6$ \\
\hline Controls: & \multicolumn{6}{|c|}{ Country dummies, continent-year dummies, log GDP per capita } \\
\hline Countries & 136 & 136 & 136 & 136 & 136 & 136 \\
\hline Observations & 2771 & 2771 & 2771 & 2771 & 2771 & 2771 \\
\hline Adjusted $R^{2}$ & 0.74 & 0.74 & 0.74 & 0.74 & 0.74 & 0.75 \\
\hline
\end{tabular}

Notes: Figures in parentheses are cluster standard errors, and they are robust to arbitrary heteroskedasticity and arbitrary intra-group correlation. ${ }^{* * *},{ }^{* *}$, and * indicate significance level at $1 \%, 5 \%$, and $10 \%$ respectively against a two sided alternative. Sample years are every year from 1980 to 2007 . Democratization $n_{\text {ict }}$ (Placebo) $=1$ (or Media Freedom $_{\text {ict }}($ Placebo) $=1$ ) at 1, 2, 3, 4, 5, 6 years before democratization with Polity2 score permanently turning positive (before media freedom status turns permanently "free"). All regressions include country fixed effects, continent-year dummies, and log GDP per capita.

now $U(0, \kappa, \underline{\theta})=u(0, \underline{\theta})+\beta p u(\kappa, \underline{\theta})$ when playing $c_{1}(\underline{\theta})=0$ in period one, and $U(\kappa, \kappa, \underline{\theta})=u(\kappa, \underline{\theta})+\beta[(1-M) p+M q] u(\kappa, \underline{\theta})$ when playing $c_{1}(\underline{\theta})=\kappa$ in period one. Hence, a bad incumbent plays $c_{1}(\underline{\theta})=0$ if and only if

$$
U(0, \kappa, \underline{\theta}) \geq U(\kappa, \kappa, \underline{\theta}) \Leftrightarrow \phi \geq \hat{\phi}^{2} \equiv 1-\beta D M,
$$

where $\phi \equiv \frac{u(0, \underline{\theta})}{u(\kappa, \underline{\theta})}$ and $D \equiv p-q$ as in Sections 2 and $3 .{ }^{19}$ This condition implies that the set of values of $\phi$ for which a bad incumbent choose not to engage in corruption in period one is the larger, the more democratic the country, the freer the media, and the higher the discount factor $\beta$. Also, democratic institutions and media freedom are again complements in the fight against corruption. Hence, the main results highlighted in Proposition 2 also hold when adding discounting to our two-period game.

\section{A.2. Infinite-horizon game}

The setting of the model is very similar to the one described in Section 2 . The only differences are that all players have a discount factor $\beta<1$, and that there is an infinite number of periods which are all identical to period one in the two-period game, so that politicians may stay in office for many periods. For simplicity, we assume that there is a zero probability that an ousted politician becomes a challenger in a later period.

First, notice that every subgame in which the incumbent is of type $\theta$ is identical. The people again support the incumbent at the end of period $t$ if and only if their updated belief that he is a good type exceeds the probability that the challenger is a good type, which is $\alpha$. Therefore, in order to determine the politicians' equilibrium strategy we only need to establish whether the expected life-time utility of an incumbent of type $\theta$ is higher when choosing $c_{t}(\theta)=0$ in the given and any future period $t$ in which he is still in office, or when choosing $c_{t}(\theta)=\kappa$ in the given and any future period $t$ in which he is still in office. It is straightforward to see that a good incumbent is better off always choosing $c_{t}(\bar{\theta})=0$. A bad incumbent's expected lifetime utility is $\sum_{i=0}^{\infty} \beta^{i-1} p^{i-1} u(0, \underline{\theta})=\frac{u(0, \underline{\theta})}{1-\beta p}$ when always choosing $c_{t}(\underline{\theta})=0$, and $\sum_{i=0}^{\infty} \beta^{i-1}[(1-M) p+M q]^{i-1} u(\kappa, \underline{\theta})=\frac{u(\kappa, \underline{\theta})}{1-\beta[(1-M) p+M q]}$ when always choosing $c_{t}(\underline{\theta})=\kappa$. Hence, the incumbent is better off when always choosing $c_{t}(\bar{\theta})=0$ if and only if

$$
\frac{u(0, \underline{\theta})}{1-\beta p} \geq \frac{u(\kappa, \underline{\theta})}{1-\beta[(1-M) p+M q]} \Leftrightarrow \phi \geq \hat{\phi}^{\infty} \equiv \frac{1-\beta p}{1-\beta[(1-M) p+M q]}=\frac{1-\beta p}{1-\beta(p-D M)}
$$

19 Observe that if $\beta=1$, this condition is identical to the condition specified in Proposition 1. 
This condition also implies that the set of values of $\phi$ for which a bad incumbent chooses not to engage in corruption in any period is the larger, the more democratic the country (i.e., the higher $p$ and the lower $q$ ), the freer the media, and the higher the discount factor $\beta$. Also, democratic institutions and media freedom can again be shown to be complements in the fight against corruption. Hence, the main results highlighted in Proposition 2 also hold in the infinite-horizon version of the game.

\section{A.3. Comparison of results}

So far, we have seen that our main results hold no matter whether we study the two-period or the infinite-horizon version of our game. We now compare the level of corruption in these two models. Corruption tends to be higher in the two-period version for two reasons. The first is rather trivial: Bad incumbents always choose high corruption in the last period, independently of the exact parameter values; and there is a last period in the two-period game, but not in the infinite-horizon game.

The second reason is slightly more subtle. The set of values of $\phi$ for which a bad incumbent, who could potentially stay in power for more periods, chooses to abstain from corruption is larger in the infinite-horizon game than in the two-period game, i.e., $\hat{\phi}^{2} \geq \hat{\phi}^{\infty}$. ${ }^{20}$ The intuition is that a bad incumbent who may stay in power and earn an official salary for many more years cares more about the chances that he can stay in power than a bad incumbent who can stay for one more year at most.

One way to think about these two versions of our game is in terms of term limits. Many countries have no restrictions on the number of terms a president can stay in office, while many others reduce it to two terms. ${ }^{21}$ The two-period version of our game may represent politics in a country with a term limit of two terms, and the infinite-horizon version may represent politics in a country without term limits. Hence, the above comparison of results suggests that term limits may increase corruption.

\section{References}

Ades, A., Di Tella, R., 1997. National champions and corruption: some unpleasant interventionist arithmetic. Econ. J. 107, $1023-1042$.

Ades, A., Di Tella, R., 1999. Rents, competition, and corruption. Am. Econ. Rev. 89, 982-993.

Adserà, A., Boix, C., Payne, M., 2003. Are you being served? Political accountability and quality of government. J. Law Econ. Org. 19, 445-490.

Aidt, T., 2003. Economic analysis of corruption: a survey. Econ. J. 113, F632-F652.

Aidt, T., Dutta, J., Sena, V., 2008. Governance regimes, corruption and growth: theory and evidence. J. Comp. Econ. 36, 195-220.

Bardhan, P., 1997. Corruption and development: a review of issues. J. Econ. Lit. 35, 1320-1346.

Barro, R., 1973. The control of politicians: an economic model. Public Choice 14, 19-42.

Besley, T., 2007. Principled Agents? The Political Economy of Good Government. Oxford University Press, Oxford.

Besley, T., Burgess, R., 2002. The political economy of government responsiveness: theory and evidence from India. Q. J. Econ. 117, $1415-1451$.

Besley, T., Prat, A., 2006. Handcuffs for the grabbing hand? Media capture and government accountability. Am. Econ. Rev. 96, 720-736.

Bhattacharyya, S., 2013. Political origins of financial structure. J. Comp. Econ. 41, 979-994.

Bhattacharyya, S., Hodler, R., 2010. Natural resources, democracy and corruption. Eur. Econ. Rev. 54, 608-621.

Brunetti, A., Weder, B., 2003. A free press is bad news for corruption. J. Public Econ. 87, 1801-1824.

Choe, C., Raschky, P.A., 2011. Media, democracy, and government action: prevention vs. palliation in the time of cholera. ISER Discussion Paper 812.

Chowdhury, S.K., 2004. The effect of democracy and press freedom on corruption: an empirical test. Econ. Lett. 85, 93-101.

Costas-Pérez, E., Solé-Ollé, A., Sorribas-Navarro, P., 2012. Corruption scandals, voter information, and accountability. Eur. J. Polit. Econ. 28 , 469-484.

Diabya, A., Sylwester, K., 2014. Bureaucratic competition and public corruption: evidence from transition countries. Eur. J. Polit. Econ. 35, $75-87$.

Ferejohn, J., 1986. Incumbent performance and electoral control. Public Choice 50, 5-25.

Ferraz, C., Finan, F., 2008. Exposing corrupt politicians: the effects of Brazil's publicly-released audits on electoral outcomes. Q. J. Econ. 123, $703-745$.

Freille, S., Haque, M.E., Kneller, R., 2007. A contribution to the empirics of press freedom and corruption. Eur. J. Polit. Econ. $23,838-862$.

Giavazzi, F., Tabellini, G., 2005. Economic and political liberalizations. J. Monet. Econ. 52, 1297-1330.

Goel, R.K., Nelson, M.A., Naretta, M.A., 2012. The internet as an indicator of corruption awareness. Eur. J. Polit. Econ. $28,64-75$.

La Porta, R., Lopez-de-Silanes, F., Shleifer, A., Vishny, R., 1999. The quality of government. J. Law Econ. Org. 15, $222-279$.

Luechinger, S., Meier, S., Stutzer, A., 2008. Bureaucratic rents and life satisfaction. J. Law Econ. Org. 24, 476-488.

Marshall, M., Jaggers, K., 2002. Polity IV Project: Political Regime Characteristics and Transitions, 1800-2002. University of Maryland.

Paldam, M., 2002. The cross-country pattern of corruption: economics, culture and the seesaw dynamics. Eur. J. Polit. Econ. 18, 215-240.

Persson, T., Tabellini, G., 2000. Political Economics: Explaining Economic Policy. MIT Press, Cambridge.

Rose-Ackerman, S., 1999. Corruption and Government: Causes, Consequences and Reform. Cambridge University Press, Cambridge.

Treisman, D., 2000. The causes of corruption: a cross-national study. J. Public Econ. 76, 399-457.

Vaidya, S., 2005. Corruption and the media's gaze. Eur. J. Polit. Econ. 21, 667-687.

Yang, B., 2011. Political democratization, economic liberalization, and growth volatility. J. Comp. Econ. 39, $245-259$.

\footnotetext{
${ }^{20}$ It holds that $\hat{\phi}^{\infty} \leq \hat{\phi}^{2} \Leftrightarrow 1-\beta p \leq(1-\beta D M)[1-\beta(p-D M)]=1-\beta p+\beta^{2} D M(p-D M)$, because $p \geq D M=(p-q) M$ and $D M \geq 0$.

21 There are very few countries with term limits that allow for only one or more than two terms.
} 